\title{
Comparative evaluation of various polishing systems on color stability of two nano composite resin restorative materials - an in vitro study
}

\author{
Anitha Rao S*, Mohini R, Chandrasekhar V and Muralidhar T \\ Department of Conservative Dentistry and Endodontics, Mamata Dental College, Khammam, India.
}

\begin{abstract}
Aim: To compare the effect of four different polishing systems on color stability of two Nano composite resins immersed in four beverages (Coffee, Tea, Cola and Fanta).

Methods: Eighty disc shaped specimens of $10 \mathrm{~mm}$ diameter and $2 \mathrm{~mm}$ thickness were prepared for each of the two Nano composite resins (Tetric N Ceram; Estelite alpha). The specimens of each material were divided into four groups ( $\mathrm{n}=20)$ and were polished by four different systems (Optrapol; Astro brush; Diamond polishing paste; Shofu super-snap polishing discs). They were then immersed in four different beverages for 10 days at room temperature (Coffee, Tea, Cola and Fanta). The color of the specimens were evaluated under spectrophotometer before and after immersion. The mean color change ( $\Delta \mathrm{E})$ values were statistically analyzed using three ways ANOVA.
\end{abstract}

Results: The color change $(\Delta \mathrm{E})$ of the two Nano-composites ranged between 4.012 and 2.474 after 10 days of immersion in staining solutions. Statistically significant difference $(\mathrm{p}<0.05)$ was observed between the staining of two Nano-composites when compared with polishing systems and staining solutions.

Conclusions: The two Nano-composites showed comparable color changes in all beverages. Estelite alpha showed greater resistance to staining as compared to Tetric N Ceram. Staining susceptibility was greater when polished by OptraPol followed by Astro brush, Diamond polishing paste and Shofu super-snap polishing discs.

Abbreviations: AB (Astro brush); DP (Diamond polishing paste);
OP (Optrapol)

\section{Introduction}

Tooth colored restorative materials are being used most often owing to their esthetic properties which determine the success along with their functional results. Many improvements have been made in the resin composites during the recent past for fulfilling the optimal esthetics. Nevertheless, the color stability of these resin composites is challenging to restorative dentistry as they are exposed to most dynamic oral environment [1].

Despite satisfying esthetic demands, many previous studies have proved that composite resins show staining susceptibility. This discoloration or staining may be caused due to various intrinsic and extrinsic factors [1]. Intrinsic factors include alterations in the resin matrix and fillers and incomplete polymerization. Extrinsic factors that contribute to discoloration include staining due to absorption or adsorption of colorants from various food beverages and surface roughness. Surface properties are further affected by the filler type, resin matrix composition [2] and finishing and polishing techniques [3]. Finishing and polishing are important steps that enhance both longevity and esthetics of the restored tooth $[3,4]$ which also influence plaque retention, periodontal disease and recurrent decay in addition to staining of composite resins [5].

Nano-composites are one of the recent and important advances in the composite resin restorative materials. They incorporate Nano- fillers in the range of 1 to $100 \mathrm{~nm}$ through nanotechnology. The advantages of Nano-composite over other composite resins are reduced polymerization shrinkage, increased mechanical properties, improved optical characteristics, better gloss retention and diminished wear [6-9].

The objectives of this in vitro study are to: (1) Compare the effects of four different polishing systems on the staining susceptibility of two Nano-composite resins after immersion in four beverages. (2) Determine which Nano-composite has the best color stability following polishing with each of the four polishing systems.

\section{Material and methods}

\section{Specimen preparation}

The two Nano-composites used in the study were Estelite alpha (Tokuyama Dental Corporation, Taitou-ku, Tokyo, Japan) and Tetric N Ceram (IvoclarVivadent AG, Schaan, Lichtenstein) (Table 1). The four polishing systems used were Optrapol (IvoclarVivadent AG,

Correspondence to: Anitha Rao S, Department of Conservative Dentistry and Endodontics, Mamata Dental College, Giriprasad Nagar, Khammam - 507002, Telangana, India; Tel: +91 9866957163; Fax: 08742 255545; E-mail: anidental@yahoo.com

Key words: color stability, nano composites, polishing systems

Received: February 02, 2016; Accepted: February 25, 2016; Published: February 29,2016 
Table 1. Composition of restorative materials used.

\begin{tabular}{|l|l|l|l|l|}
\hline Material & Manufacturer & Filler composition & Filler weight (\%) & Filler volume (\%) \\
\hline Estelite alpha & $\begin{array}{l}\text { Tokuyama Dental corporation, } \\
\text { Tokyo, Japan }\end{array}$ & Silica, zirconia & 82 & 71 \\
\hline Tetric N Ceram & $\begin{array}{l}\text { Ivoclar Vivadent AG, Schaan, } \\
\text { Liechtenstein }\end{array}$ & $\begin{array}{l}\text { Barium glass, Ytterbium } \\
\text { trifluoride, Highly dispersed } \\
\text { silica and mixed oxide }\end{array}$ & 63 & 021 E63 \\
\hline
\end{tabular}

Table 2. Three-way ANOVA of color change, comparison between composite materials, polishing systems and staining solutions.

\begin{tabular}{|c|c|c|c|c|c|}
\hline Source & Type III Sum of Squares & df & Mean Square & $\mathbf{F}$ & p value \\
\hline Model & $1798.494^{\mathrm{a}}$ & 32 & 56.203 & 20063.522 & $.0001 *$ \\
\hline Material & 0.271 & 1 & 0.271 & 96.894 & $.0001 *$ \\
\hline Polish & 4.756 & 3 & 1.585 & 565.984 & $.0001^{*}$ \\
\hline Solution & 9.461 & 3 & 3.154 & 1125.828 & $.0001^{*}$ \\
\hline Material * Polish & 0.707 & 3 & 0.236 & 84.161 & $.0001^{*}$ \\
\hline Material * Solution & 0.145 & 3 & 0.048 & 17.265 & $.0001^{*}$ \\
\hline Polish * Solution & 0.397 & 9 & 0.044 & 15.744 & $.0001 *$ \\
\hline Material * Polish * Solution & 0.331 & 9 & 0.037 & 13.114 & $.0001 *$ \\
\hline Error & 0.359 & 128 & 0.003 & & \\
\hline Total & 1798.853 & 160 & & & \\
\hline
\end{tabular}

a. $\mathrm{R}$ Squared $=1.000$ (Adjusted R Squared $=1.000)$

* Significant $(\mathrm{p}<0.05)$

Schaan, Lichtenstein); Astro brush (IvoclarVivadent AG, Schaan, Lichtenstein); Diamond polishing paste (Shofu Inc., Kyoto, Japan); and Shofu super-snap polishing discs (Shofu Inc., Kyoto, Japan). Eighty disc shaped specimens of $10 \mathrm{~mm}$ diameter and $2 \mathrm{~mm}$ thickness were prepared for each of the Nano-composites. The material was carried into a polytetrafluoroethylene mold and covered by mylar strips (Mylar, Henry Schein, Melville, NY, USA) on either side and are placed between $1 \mathrm{~mm}$ thick glass slides. It was then light cured for 40 seconds on either side (LEDition, IvoclarVivadent AG, Schaan, Lichtenstein). To ensure maximum polymerization, all specimens were stored in distilled water for 24 hours at $37^{\circ} \mathrm{C}$.

\section{Polishing}

The specimens were divided into four groups based on the polishing system used. In first group, Optrapol (OP) polishing cup was used for $60 \mathrm{sec}$ in a low speed contra-angled hand piece under water spray. In the second group, Astro brush (AB) was used in the same manner for $60 \mathrm{sec}$. In the third group, Shofu super-snap polishing discs were used from coarse to superfine each for $15 \mathrm{sec}$, for a total of $60 \mathrm{sec}$. In the fourth group, Diamond polishing paste (DP) was applied on the discs and polished with the buff disc, as recommended by the manufacturer for $60 \mathrm{sec}$. For all specimens, the baseline color was measured by spectrophotometer.

\section{Staining}

The specimens in each group were divided into four sub-groups $(n=5)$, and were immersed in four different beverages, Coffee, Tea, Cola and Fanta. Coffee was prepared by mixing $2 \mathrm{gm}$ of instant Coffee powder (BRU instant, Hindustan Unilever LTD, India) in $100 \mathrm{ml}$ of boiling water for 1 minute, and the solution was filtered ..... Tea was prepared by immersing 2 gm of prefabricated Tea bag (Brooke Bond TajMahal, Hindustan Unilever LTD, India) in $100 \mathrm{ml}$ of boiling water for 5 minutes. $20 \mathrm{ml}$ of each solution; Coffee, Tea, Cola (The CocaCola Company, Atlanta, USA), and Fanta (The Coca-Cola Company, Atlanta, USA) were taken. Immersion period was standardized as 10 days. The solutions were replenished every third day to prevent contamination by yeast orbacteria. After staining period, the color of the specimens were measured by spectrophotometer. The change in color before and after immersion were calculated by the formula

$$
\Delta \mathrm{E}=\left[\left(\Delta \mathrm{L}^{*}\right)^{2}+\left(\Delta \mathrm{a}^{*}\right)^{2}+\left(\Delta \mathrm{b}^{*}\right)^{2}\right]^{1 / 2}
$$

where $L^{*}$ is lightness, $a^{*}$ is green-red $\left(-a=\right.$ green; $+a=$ red) and $b^{*}$ is blue-yellow $(-b=$ blue; $+b=$ yellow $)$.

\section{Statistical analysis}

Data were evaluated to check the equality of variances and confirm a normal distribution. Color change $(\Delta \mathrm{E})$ data were subjected to threeway ANOVA, with a significance level of $5 \%$.

\section{Results}

Regarding the color change, there was a significant interaction between the factors "materials" and "polishing systems" $(\mathrm{p}<0.0001)$ and also between "solutions" and "polishing systems" $(\mathrm{p}<0.0001)$ (Table 2). There was a significant difference among the three factors (material, polishing system and solution) $(\mathrm{p}<0.0001)$.

The mean and standard deviations of color change values of each material after polishing with different polishing systems and immersion in staining solutions are presented in Table 3 . When different solutions were compared concerning each material after polishing, there was significant difference in the color change $(\mathrm{p}<0.05)$. Tetric $\mathrm{N}$ Ceram did not show statistically significant difference in color change after immersion in Coffee and Tea; and in some sub-groups of Cola and Fanta. ( $p>0.05)$. There was also significant difference in color change between two Nano-composites $(\mathrm{p}<0.05)$ for each polishing system and solution. When polishing systems were compared, there was significant difference in color change $(\mathrm{p}<0.05)$ for each system within each material and solution.

\section{Discussion}

Proper finishing and polishing of composite restorations not only enhances the esthetics, but also aids in longevity of the restoration. 
Table 3. Color change $(\Delta \mathrm{E})$ mean (standard deviation in parentheses) of Nano-composites polished by different polishing systems.

\begin{tabular}{|c|c|c|c|c|c|}
\hline \multirow[t]{2}{*}{ Material } & \multirow[t]{2}{*}{ Polishing System } & \multicolumn{4}{|c|}{ Solutions } \\
\hline & & Coffee & Tea & Cola & Fanta \\
\hline \multirow[t]{4}{*}{ Estelite Alpha } & OP & *3.836 (0.009) Aa & *3.578 (0.008) Ba & *3.066 (0.011) Ca & *3.312(0.008) Da \\
\hline & AB & & *3.376 (0.021) Bbc & *3.012 (0.013) Cb & *3.260 (0.019) Db \\
\hline & Soflex & & $* 3.346(0.011) \mathrm{Bb}$ & $* 2.882(0.013) \mathrm{Cc}$ & *3.010 (0.010) Dc \\
\hline & DP & *3.488 (0.013) Ad & $* 3.706(0.009) \mathrm{Ab}$ & $* 2.992(0.013) \mathrm{Cbd}$ & *3.086 (0.011) Dd \\
\hline \multirow[t]{4}{*}{ Tetric n Cream } & OP & $4.012(0.008) \mathrm{Aa}$ & $* 3.412(0.013) \mathrm{Ac}$ & $3.300(0.019) \mathrm{Ca}$ & $3.620(0.084) \mathrm{Da}$ \\
\hline & $\mathbf{A B}$ & $3.526(0.239) \mathrm{Ab}$ & $3.618(0.015) \mathrm{Ab}$ & $3.166(0.015) \mathrm{Bb}$ & $3.380(0.084) \mathrm{Bb}$ \\
\hline & Soflex & $3.290(0.010) \mathrm{Ac}$ & $3.254(0.011) \mathrm{Ac}$ & $2.474(0.023) \mathrm{Bc}$ & $3.154(0.047) \mathrm{Cc}$ \\
\hline & DP & $3.582(0.015) \mathrm{Abd}$ & $3.470(0.021) \mathrm{Ad}$ & $3.038(0.031) \mathrm{Bd}$ & $3.230(0.095) \mathrm{Ccd}$ \\
\hline
\end{tabular}

Capital letters indicate comparison among solutions (Horizontal). Lowercase letters demonstrate comparison among polishing systems (vertical) within each solution and each material Asterisks $(*)$ represent significant difference among Materials (Estelite Alpha vs Tetric n Cream) within each polishing system and solutions. Groups denoted by same letter / symbol represent no significant difference $(\mathrm{p}>0.05)$.

They also influence the composite surface quality and can therefore be related to early discoloration of the resin-based materials [10]. The staining of composite resins by colored solutions such as Coffee, Tea [11], and beverages [1]. has been reported. In the present study, staining susceptibility of two Nano-composite resins polished by different polishing systems was evaluated after immersion in four beverages, Coffee, Tea, Cola and Fanta. Coffee, Tea, Cola, and Fanta (orange juice) are the most commonly consumed beverages in day to day life, of which Cola and Fanta are carbonated.

In the present study, all specimens showed color change from baseline value. Staining susceptibility was measured on the basis of $\Delta \mathrm{E}$ values. Clinically acceptable value of $\Delta \mathrm{E}$ in dentistry is $\leq 3.3 . \Delta \mathrm{E}$ values $>3.3$ were shown by the Nano-composite resins after immersion in coffee, and in some groups tea and Fanta. The effect of staining solution on color change was material dependent. Staining by Coffee and Tea might be because of adsorption and absorption, as stated by previous studies $[1,12]$. The degree of conversion of polymer can affect the staining of composites, but the direct relation between degree of conversion and staining has not been established. In a study done by Al Kheraif et al. [13] (2013), Nano-composites showed more staining than microhybrid composites, though their degree of conversion was high. In contrast to the above mentioned study, Reddy et al. [14] (2013) reported that less color change was shown by Nano-composite than microhybrid and hybrid composites. But in the present study, comparison was done only between two nano-composites.

The four polishing systems tested showed significant differences $(p<0.05)$ in staining of the Nano-composites. Higher $\Delta \mathrm{E}$ values were observed when Nano-composites were polished by OptraPol, followed by Astro brush, diamond polishing paste and Shofu supersnap polishing discs. Study done by Ergücü and Türkü [15] (2007) on the surface roughness of five Nano-composites after polishing with three one-step polishing systems revealed that OptraPol and One Gloss created rougher surfaces and the particles were plucked away from the surface. One step polishing systems (OptraPol, Astro brush, Diamond polishing paste) showed less resistance to staining than multi-step polishing system (Shofu super-snap polishing discs). This is in accordance with the study done by Kumari RV et al. [16] (2015) who concluded that Sof-Lex polishing system makes the nano-composite resin more resistant to discoloration, compared to the Diamond polishing paste.

Significant difference $(\mathrm{p}<0.05)$ was observed between the two nanocomposite resins with greater staining exhibited by Tetric N Ceram. This may be because of difference in matrix and filler composition and also the filler size and shape which in turn effect the surface roughness of the composite resin.

The lower staining susceptibility of Estelite Alpha can also be attributed to its shape of the filler particles. Manufacturer claims that the filler particles in Estelite Alpha are spherical in shape, which are produced by Sol-gel method, in contrast to other Nano-composites where the fillers are produced by conventional smash of bulk metal alkoxides. Spherical filler particles might have contributed to less surface irregularities during polishing in comparison with Tetric $\mathrm{N}$ Ceram.

Though laboratory studies give satisfactory results, composites are susceptible to discoloration over long periods of time, as suggested by some clinical trials [17]. Further long term clinical trials are necessary to determine the color stability of these composites in oral environment.

\section{Conclusions}

Based on the results of the present study, it can be concluded that the two Nano-composites showed comparable color changes in all beverages. Nano-composite Estelite alpha showed greater resistance to staining as compared to Tetric N Ceram. Staining susceptibility was greater when polished by OptraPol followed by Astro brush, Diamond polishing paste and Shofu super-snap discs.

\section{References}

1. Hotwani K, Thosar N, Baliga S (2014) Comparative in vitro assessment of color stability of hybrid esthetic restorative materials against various children's beverages. $J$ Conserv Dent 17: 70-74. [Crossref]

2. Chung KH (1994) Effects of finishing and polishing procedures on the surface texture of resin composites. Dent Mater 10: 325-330. [Crossref]

3. Jefferies SR (1998) The art and science of abrasive finishing and polishing in restorative dentistry. Dent Clin North Am 42: 613-627. [Crossref]

4. Goldstein RE (1989) Finishing of composites and laminates. Dent Clin North Am 33: 305-318. [Crossref]

5. Bollen CML, Lambrechts P, Quirynen M (1997) Comparison of surface roughness of oral hard materials to the threshold surface roughness for bacterial plaque retention: a review of literature. Dent Mater 13: 258-369.

6. Moszner N, Salz U (2001) New developments of polymeric dental composites. Prog Polym Sci 26: 535-576.

7. Moszner N, Klapdohr S (2004) Nanotechnology for dental composites. Int $J$ Nanotechnol 1: 130-156.

8. Mitra SB, Wu D, Holmes BN (2003) An application of nanotechnology in advanced dental materials. J Am Dent Assoc 134: 1382-1390. [Crossref]

9. Terry DA (2004) Direct applications of a nanocomposite resin system. Part 1. The evolution of contemporary composite materials. Pract Proced Aesthet Dent 16: 417422. [Crossref] 
10. Fay RM, Servos T, Powers JM (1999) Color of restorative materials after staining and bleaching. Oper Dent 24: 292-296. [Crossref]

11. Um CM, Ruyter IE (1991) Staining of resin-based veneering materials with coffee and tea. Quintessence Int 22: 377-86. [Crossref]

12. Bagheri R, Burrow MF, Tyas M (2005) Influence of food simulating solutions and surface finish on susceptibility to staining of aesthetic restorative materials. $J$ Dent 33 : 389-398. [Crossref]

13. Al Kheraif AA, Qasim SS, Ramakrishnaiah R, Ihtesham ur Rehman (2013) Effect of different beverages on the color stability and degree of conversion of nano and microhybrid composites. Dent Mater J 32: 326-331. [Crossref]

14. Reddy PS, Tejaswi KL, Shetty S, Annapoorna BM, Pujari SC, et al. (2013) Effects of commonly consumed beverages on surface roughness and color stability of the nano, microhybrid and hybrid composite resins: an in vitro study. $J$ Contemp Dent Pract 14 718-723. [Crossref]

15. Ergücü Z, Türkün LS (2007) Surface roughness of novel resin composites polished with one-step systems. Oper Dent 32: 185-192. [Crossref]

16. Kumari RV, Nagaraj H, Siddaraju K, Poluri RK (2015) Evaluation of the Effect of Surface Polishing, Oral Beverages and Food Colorants on Color Stability and Surface Roughness of Nanocomposite Resins. J Int Oral Health 7: 63-70. [Crossref]

17. Ardu S, Braut V, Gutemberg D, Krejci I, Dietschi D, Feilzer AJ (2010) A long term laboratory test on staining susceptibility of esthetic composite resin materials Quintessence Int 41: 695-702. [Crossref]

Copyright: @2016 Anitha Rao S. This is an open-access article distributed under the terms of the Creative Commons Attribution License, which permits unrestricted use, distribution, and reproduction in any medium, provided the original author and source are credited. 